\title{
Selective conservative treatment for anterior abdominal gunshot: a literature narrative review
}

\section{Tratamento seletivo não operatório para ferimentos penetrantes por projeteis de arma de fogo na parede anterior do abdome: revisão narrativa da literatura}

Francisco Eduardo Sillva'id; Bruna de Carvalho Sorrentino'.

\begin{abstract}
A B S T R A C T
The nonoperative treatment of anterior abdominal gunshot wounds remains controversial. This article presents a narrative review of the literature after the selection of studies in electronic databases (PubMed, Cochrane Library and Lilacs), with the intention of evaluating the clinical and diagnostic tools that should be part of conservative selective approach of these lesions. It was observed that a nonoperative selective treatment can be effectively and safely used, when performed by a trained interdisciplinary team, working in adequate trauma centers. The selective nonoperative treatment is associated with a decrease in negative and nontherapeutic laparotomies, reducing the incidence of complications. It also contributes to the reduction of hospital costs.
\end{abstract}

Keywords: Abdominal Wall. Abdominal Injuries. Wounds, Stab. Wounds, Gunshot. Surgical Procedures, Operative.

\section{INTRODUCTION}

S

urgical treatment of gunshot wounds that penetrate the abdominal cavity is the traditional, standard one'. In the 1960s, Shaftan suggested the term "Selective Conservatism" referring to the conservative treatment of abdominal injuries from knives ${ }^{2}$. Since then, nonoperative treatment of wounds by this type of weapon has been widespread in major trauma centers around the world. The injuries caused by firearm projectiles in the abdominal cavity, however, are still treated with mandatory surgical exploration in most hospitals. The reason for this conduct is that these wounds are still believed to cause a high incidence of intra-abdominal injuries, and that the occurrence of complications in a negative laparotomy would not justify an attempt of conservative treatment in such injuries.
The worldwide trend to always intervene surgically in this type of injury is still well accepted in most services for traumatized victims of abdominal perforations caused by firearm projectiles. The lack of scientific evidence and protocols also corroborates to maintain surgical treatment as the standard one $\mathrm{e}^{1,3,4}$.

The aim of this study is to make a bibliographic survey of the most relevant articles published in electronic databases by doing a narrative review of the literature on the nonoperative, selective treatment of gunshot abdominal injuries, emphasizing the selective conservatism.

\section{METHODS}

This study is a review of the specialized literature. We performed an electronic search of

1 - Federal University of Rio de Janeiro, Department of Surgery - Macae - RJ - Brazil 
databases for articles and publications related to the nonoperative treatment of penetrating abdominal gunshot injuries. We searched the databases PubMed, Cochrane Library and Lilacs, including studies published until January 2020. We carried out the study in the Surgery Department of the Federal University of Rio de Janeiro - Macaé Campus.

The keywords and descriptors used to search for articles in the databases were "gunshot wound", "abdominal", "selective", "treatment" and "nonoperative management". We reproduce the search format in the PubMed database (PubMed Search Builder) below:

(("abdomen" [MeSH Terms] OR "abdomen" [All Fields] OR "abdominal" [All Fields]) AND ("wounds, gunshot" [MeSH Terms] OR ("wounds" [All Fields] AND "gunshot" [All Fields]) OR "gunshot wounds" [All Fields] OR ("gunshot" [All Fields] AND "wounds" [All Fields]))) AND nonoperative [All Fields] AND "humans" [MeSH Terms]

The inclusion criterion used for this review was the selection of articles addressing the non-surgical treatment of gunshot injuries to the anterior region of the abdomen. We excluded articles that addressed perforating abdominal injuries for causes other than firearms.

We identified 148 articles, without assessing the degree of scientific evidence, as this is a literature review article. We selected all types of studies that addressed the topic. We evaluated each identified study by title and abstract. We excluded duplicate articles, and included in the review studies that addressed gunshot wounds to the anterior abdomen. Then, we studied the articles to understand the main parameters and forms of application employed in the conservative treatment of such injuries.

\section{RESULTS}

From the 148 studies identified in the electronic database searches, we excluded 16 duplicates. Based on the title and abstract, we looked for relevant papers, addressing the conservative treatment of abdominal gunshot wounds, selecting 12 articles on the topic (Figure 1).

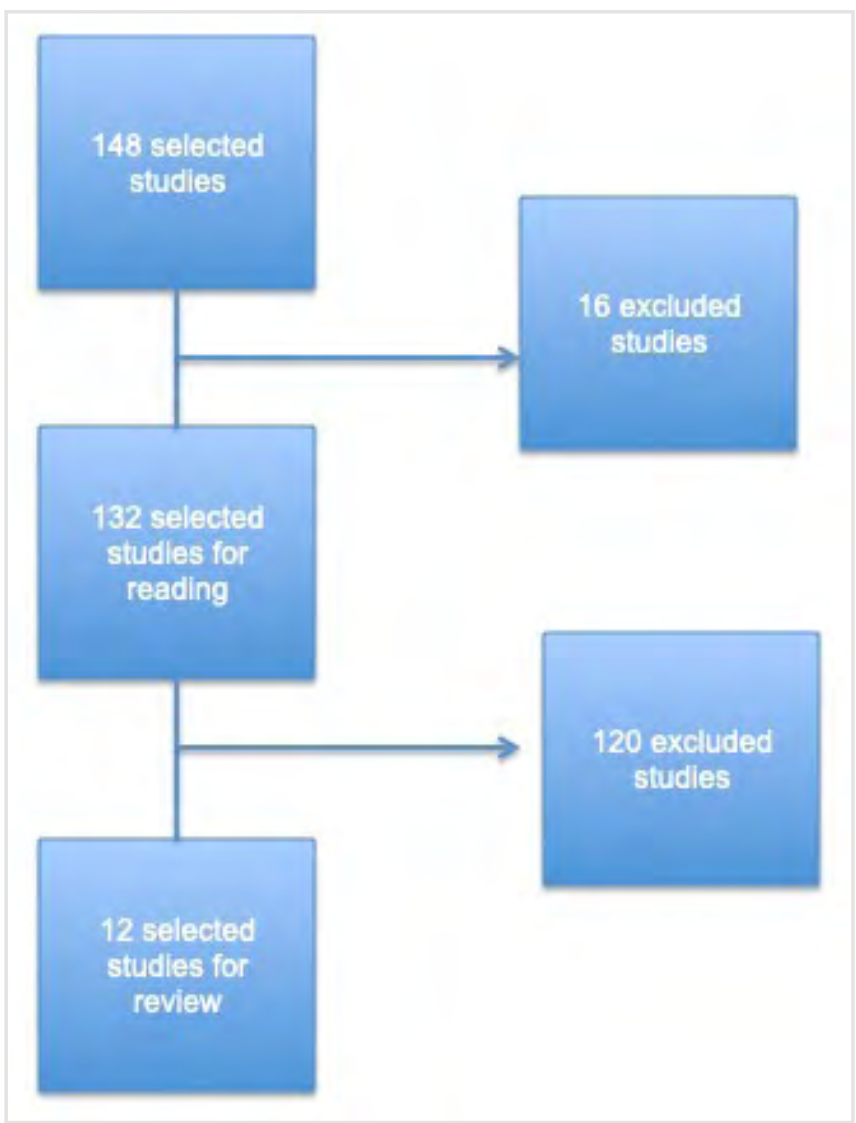

Figure 1. Flowchart regarding the data base electronic search (references of the included articles - 1, 5, 6, 7, 8, 9, 10, 11, 12, 13, 14, 15).

\section{DISCUSSION}

Until the 19th century, penetrating wounds in the abdominal cavity were treated conservatively, rendering a high mortality rate. During the First World War, the choice of surgical treatment for penetrating wounds of the abdomen came to be considered the most appropriate way to manage these types of injuries. In the 1960s, Shaftan proposed a "Selective Conservatism" for penetrating abdominal injuries ${ }^{2}$. However, this is not a new concept. In the pre-anesthetic era, this conduct was practiced out of necessity, often with unfavorable results and a high mortality rate 12,16. $^{2}$ In 1969, Nance and Cohn reiterated this theory for stabbing abdominal injuries ${ }^{17}$. Since then, the selective nonoperative management for abdominal cavity stab wounds has been widely accepted, which has not been the case for those caused by firearm projectiles. The term selective conservatism does not only mean the 
act of not operating selected individuals, but is based primarily on clinical surveillance and serial reevaluation of patients.

The authors who defend the surgical treatment of gunshot wounds at the expense of a nonoperative conduct claim that clinical examination is not reliable to determine the severity of the selected cases, that the risk of injury to intra-abdominal organs is very high and, finally, that non-therapeutic laparotomies can be benign if compared to the severity of an intra-abdominal injury that may go unnoticed ${ }^{11,12}$.

Within the context of selective conservatism, we can discuss these statements based on publications in the world literature, involving some prospective studies, even without high-quality scientific evidence. The first argument may become invalid when considering the results of several studies in which the authors demonstrated a high level of sensitivity and specificity for serial clinical examinations as an important method to assess the need or not for urgent laparotomy. As an example of this conduct, we found the studies of Velmahos et al., in 1997 (sensitivity: 100\%; specificity: 95.3\%) ${ }^{18}$ and Demetriades et al., in 1997 (sensitivity: $97.1 \%)^{19}$. Regarding the second argument described above, it is true that the risk of unnoticed injury to intra-abdominal organs is high. Such injuries, however, often have no clinical repercussions ${ }^{12,16}$. Examples would be kidney and right liver injuries, which can often be successfully treated conservatively (Renz and Feliciano, 1994; Velmahos et al., 1998; Wood et al., 2010)10,11. Finally, the last argument of the authors who defend the surgical approach can be contested too, since non-therapeutic laparotomies are not benign. On the contrary, they can bring immediate or long-term harm to the patient. Among the early complications, we can mention intra-abdominal and surgical wound infections, early intestinal obstruction, respiratory complications and even death. Incisional hernias and intestinal obstruction are among the most common late complications in cases of non-therapeutic surgical treatment (Leppaniemi et al., 1995; Weigelt and Kingman, 1988)3. In addition, non-therapeutic laparotomies generate higher hospital costs and may increase the length of hospital stay.

The definition of non-therapeutic laparotomy is when intra-abdominal injuries are found at the time of surgery, but no intervention is necessary for treatment, as they are injuries of low complexity and severity, often with a self-limited, favorable evolution. Negative laparotomy is when no intra-abdominal changes or injuries are found after the violation of the peritoneum. Positive or therapeutic laparotomy consists of finding and treating organ damage in the abdominal cavity?

Two large studies conducted in South Africa in the 1990s demonstrated success in conservative, selective treatment of patients with gunshot injuries. In the first, Muckart et al. ${ }^{20}$ selected 111 patients, 89 $(80 \%)$ of whom underwent immediate laparotomy and $22(20 \%)$ received conservative treatment. None of the patients required late laparotomy. Thus, the authors concluded that a selected group of patients could undergo the conservative approach. In the second study, Demetriades et al. ${ }^{4}$, in 1991, evaluated 146 victims of penetrating gunshot wounds, 41 being initially treated nonoperatively. Subsequently, seven patients required late laparotomy, this leading to no increased morbidity or mortality ${ }^{4,16}$.

The vast majority of patients who underwent conservative treatment needed to be observed for a period of 24 hours, and then were able to be discharged. Velmahos et al. ${ }^{18}$, in 1997, evaluated patients with penetrating gunshot wounds, and stated that an observation longer than 24 hours becomes unnecessary in patients who are stable, are accepting diet and who do not show symptoms/signs ${ }^{11}$.

In 2010, the Eastern Association for the Surgery of Trauma published a guideline whose purpose was to assist and guide surgeons in the proper management of victims of injuries from perforating objects in the abdominal cavity. According to the manual, patients with hemodynamic instability or diffuse peritonitis are eligible for immediate laparotomy. For patients unable to undergo an adequate clinical examination (severe skull or spinal cord trauma, exogenous intoxication, and requiring sedation or endotracheal intubation), nonoperative treatment is contraindicated and laparotomy should be performed. Victims of penetrating gunshot injury to the abdomen who arrive with hemodynamic stability or without signs of diffuse peritonitis can be managed conservatively. The 
criteria for non-surgical decision-making will depend on surveillance by the surgical team that will evaluate and manage these patients clinically. Changes in the presentation, with clinical signs of diffuse peritonitis or the decrease in hematocrit, will indicate the need for surgical management. In this way, a surgeon well trained in this type of therapeutic approach can reduce the number of unnecessary laparotomies, while minimizing the risk of unnoticed injuries ${ }^{10,11}$.

A correct approach when adopting selective conservatism of abdominal gunshot injuries requires a trained and vigilant surgical team, as well as the implantation of specific protocols in the services that provide care to highly complex trauma victims and are able to offer this type of treatment, without harm to the individual. Some important factors in the clinical examination of such patients must be assessed and noted accurately, such as regular measurement of systemic blood pressure, heart and respiratory rates, diuresis, as well as clinical evaluation of abdominal pain, the appearance of fever, and abnormal level of consciousness. Thus, the participation of the interdisciplinary team in this process is essential, since vital signs must be reassessed every four hours by a trained nursing team, working together with the surgical team".
In addition, complementary exams for selected patients also assist in decision making, such as serial hematocrit measurements, chest and abdomen radiographs, computed tomography of the abdomen and pelvis with triple contrast ${ }^{13,21}$, Focused Assessment with Sonography for Trauma (FAST), rigid sigmoidoscopy, intravenous pyelocystography, contrast cystography, and diagnostic laparoscopy. According to the studies evaluated, it is of great importance that the surgeon and the team that performs the first care, upon deciding for non-surgical treatment, perform the subsequent clinical reassessments. It is of utmost importance that this type of treatment be carried out in specialized centers, with a team of qualified professionals working together and with appropriate training, and that some medical specialties are on call, or at least easily accessible 9,11,13-16.

Thus, selective, nonoperative treatment of gunshot wounds to the abdomen can be safely conducted in selected patients. Absence of clinical signs of peritonitis, presence of hemodynamic stability and absence of factors that may mask the physical examination, such as low level of consciousness, may allow for nonoperative treatment, associated with imaging, laboratory tests and a trained multidisciplinary staff.

\section{R E S U M O}

O tratamento não operatório de ferimentos abdominais causados por projéteis de armas de fogo ocorridos na região anterior do abdome permanece controverso. Este artigo apresenta revisão narrativa da literatura após a seleção de estudos levantados em bancos de dados eletrônicos (PubMed, Cochrane Library e Lilacs), com a intenção de avaliar os parâmetros clínicos e exames de diagnóstico que deverão fazer parte do da abordagem conservadora seletiva dessas lesões. Avaliando os estudos selecionados, foi verificado que conduta não operatória seletiva pode ser empregada de forma eficaz e segura, quando realizada por equipe interdisciplinar treinada, atuando em Centros de Traumas adequados para a realização deste tipo de atendimento. O tratamento não operatório seletivo está associado à diminuição de laparotomias negativas e não terapêuticas, reduzindo a incidência de complicações, além de colaborar para a diminuição dos custos hospitalares.

Palavras chave: Parede Abdominal. Traumatismos Abdominais. Ferimentos Perfurantes. Ferimentos por Arma de Fogo. Procedimentos Cirúrgicos Operatórios.

\section{REFERÊNCIAS}

1. Singh N, Hardcasttle TC. Selective non operative management of gunshot wounds to the abdome: a collective review. Int Emerg Nurs. 2015;23(1):22-31.

2. Shaftan GW. Selective conservatism in penetrating abdominal trauma. J Trauma. 1969;9(12):1026-8.

3. Biffl WL, Leppainiemi A. Management guidelines for penetrating abdominal trauma world. World J Surg.
2015;39(6):1373-80.

4. Demetriades $D$, Charalambides $D$, Lahhoo $M$, Pantanowitz D. Gunshot wound of the abdome: role of selective conservative management. $\mathrm{Br}$ J Surg. $1991 ; 78(2): 220-2$.

5. Leppäniemi $A$. Nonoperative management of solid abdominal organ injuries: From past to present. Scand J Surg. 2019;108(2):95-100.

6. Al Rawahi AN, Al Hinai FA, Boyd JM, Doig CJ, Ball 
CG, Velmahos GC, et al. Outcomes of selective nonoperative management of civilian abdominal gunshot wounds: a systematic review and metaanalysis. World J Emerg Surg. 2018;13:55.

7. Peponis T, Kasotakis G, Yu J, Alouidor R, Burkott B, Maung $A A$, et al. Selective nonoperative management of abdominal gunshot wounds from heresy to adoption: a multicenter study of the Research Consortium of New England Centers for Trauma (ReCoNECT). J Am Coll Surg. 2017;224(6):1036-45.

8. Reed BL, Patel NJ, McDonald AA, Baughman WC, Claridge JA, Como JJ. Selective nonoperative management of abdominal gunshot wounds with isolated solid organ injury. Am J Surg. 2017;213(3):583-5.

9. Lamb CM, Garner JP. Selective non-operative management of civilian gunshot wounds to the abdomen: a systematic review of the evidence. Injury. 2014;45 (4):659-66.

10. Pryor JP, Reilly PM, Dobrowski GP, Grossman MD, Schwab CW. Nonoperative management of abdominal gunshot wounds. Ann Emerg Med. 2004;43(3):344-53.

11. Demetriades D, Hadjazacharia P, Constantinou C, Brown C, Inaba K, Rhee P, et al. Selective nonoperative management of penetrating abdominal solid organ injuries. Ann Surg. 2006; 244(4):620-8.

12. Salim A, Velmahos GC. When to operate on abdominal gunshot wounds. Scand J Surg. 2002;91(1):62-6.

13. Navsaria PH, Nicol AJ, Edu S, Gandhi R, Ball CG. Selective nonoperative management in 1106 patients with abdominal gunshot wounds: conclusions on safety, efficacy, and the role of selective CT imaging in a prospective single-center study. Ann Surg. 2015;261(4):760-4.

14. Fikry K, Velmahos GC, Barros A, Janjua S, de Moya

Received in: 02/03/2020

Accepted for publication: 26/03/2020

Conflict of interest: no.

Funding source: none.
$M$, King DR, et al. Successful selective nonoperative management of abdominal gunshot wounds despite low penetrating trauma volumes. Arch Surg. 2011;146(5):528-32.

15. Starling SV, Rodrigues BL, Martins MPR, Silva MSA, Drumond DAF. Tratamento não operatório do ferimento por arma de fogo na região tooracoabdominal direita. Rev Col Bras Cir. 2012;39(4):286-94.

16. Velmahos GC, Demetriades $D$, Toutouzas $K G$, Sarkisyan G, Chan LS, Ishak $R$, et al. Selective nonoperative management in 1,856 patients with abdominal gunshot wounds: should routine laparotomy still be the standard of care? Ann Surg. 2001;234(3):395-402.

17. Nance FC, Cohn I Jr. Surgical judgment in the management of stab wounds to the abdomen. A retrospective and prospective analysis based on a study of 600 stabbed patients. Ann Surg. 1969;170(4):569-80.

18. Velmahos $G C$, Demetriades D, Foianini E, Tatevossian $\mathrm{R}$, Cornwell EE 3rd, Asensio J, et al. A selective approach to the management of gunshot wounds to the back. Am J Surg. 1997;174(3):342-6.

19. Demetriades D, Velmahos G, Cornwell $E$, Berne TV, Cober S, Bhasin PS, et al. Selective Nonoperative Management of Gunshot Wounds of the Anterior Abdomen. Clinical Trial. Arch Surg. 1997;132(2):178-83.

20. Muckart DJ, Abdool-Carrim AT, King B. Selective conservatibe management of abdominal gunshot wounds: a prospective study. $\mathrm{Br}$ J Surg. 1990;77(6):652-5.

21. Múnera F, Morales C, Soto JA, Garcia HI, Suarez T, Garcia V, et al. Gunshot wounds of abdomen: evaluation of stable patients with triple-contrast helical CT. Radiology. 2004;231(2):399-405.

\section{Mailing address:}

Francisco Eduardo Silva

E-mail: dr.francisco.eduardo@gmail.com/franciscoeduardo @yahoo.com 